\title{
Engineering and Marine Exhibition at Olympia
}

$\mathrm{A}^{\mathrm{T}}$ $\mathrm{T}$ this Exhibition, which will remain open until October 2, there is so much of scientific interest that it is possible only to select a few representative items as indicative of the extent to which the results of research are being utilized with the aid of mechanical ingenuity. One gets, for example, a definite impression of a universal effort being made to deal with the problem of noise both by improvements in design and workmanship and by the adoption of new types. At one stand a noiseless sliding door is exhibited, and of silently operating machinery a notable example is the Mirrlees-Imo pump for oils and other liquids. This has only three moving parts-a central screw which is the actual pumping unit, and two side screws which act as seals and are rotated merely by their engagement with the central screw. In high-speed Diesel engines vibration is destructive of the exhaust pyrometers which, by the close relationship between exhaust temperature and horse power, are necessary to ensure that an even and efficient balance is maintained between the several cylinders. Messrs. Negretti and Zambra are exhibiting pyrometers in which a few inches of the tube immediately below the instrument have been replaced by a helical spring, and instruments so constructed are to be seen mounted on a vibrating table yet relatively unaffected.

The hygienic importance of the reduction of dust lends interest to means for its measurement, and the Tyndallometer shown by E. Leitz (London) provides a new and rapid means of its measurement. It consists of a dust chamber, a photometer head, an observation telescope and the necessary means of illumination. In the field of view is a beam of the scattered light and a comparison beam and, when these are equalized, the scale reading and the calibration curve give an instantaneous value for the dust content. On the same stand is shown a simple profile projector for the metal industry with several other optical aids. Messrs. Kelvin, Bottomley and Baird, Ltd., have on view the colour vision lantern developed by Dr. L. C. Martin in collaboration with the Medical Research Council, and also the K.B.B. Cabinet for ultra-violet fluorescence. The latter can be seen in operation with a very representative group of samples which illustrate its value in scientific testing and research, and also in industrial, medical, police and other investigations. In Messrs. Avery's recent design of Brinell and diamond impression testing machine the arrangement is such as to enable results to be obtained very rapidly, and in this respect alone this exhibit marks an advance on the usual design.

Under modern conditions, metals are frequently required to conform to very severe specifications, and Barronia Metals, Ltd., are exhibiting examples of many such problems which they have solved. One of these was the preparation of a non-ferrous alloy with a coefficient of expansion greater than steel for use with a hydrocarbon gas containing sulphur at a pressure of $200 \mathrm{lb}$. per sq. inch and a temperature of $1150^{\circ} \mathrm{F}$. Other instances of new developments in manufacture of materials are the glass cloth now being made by Chance Bros. and Co., Ltd., to replace asbestos cloth in low-temperature services and likely also to develop in decorative and other directions, and the method of electric forging which has been brought to a fine art by Messrs. Omes, Ltd. The samples of forgings exhibited indicate the wide application of the process and the high quality both of material and of surface which is obtainable. In conjunction with H. A. Brassert and Co., Ltd., Messrs. Imperial Chemical Industries Ltd. illustrate the Brassert process for acid burdening the blast furnace. By regulating the flux so as to form slag of the lowest possible melting point and viscosity, iron production is increased while less coke is used and low-grade ores can be dealt with. As a result also of the sodium carbonate treatment there is a reduction of sulphur and, due to oxidation, of silicon content. The Macrome treatment of tool steel by an electric process, applied after the usual heat treatments have been given, is claimed by Messrs. Macrome Ltd. to increase the working life of tools by $50-300$ per cent according to the steel treated and the work performed. An electric process exhibited by the O.C.P. Company is that for conditioning water and preventing scale in boilers. The water is made to pass through tubes each containing an electrode, and this process effects a physical change in the mineral salts which, on being heated, appear as erystals and do not build up scale. The elimination of chemical treatment is an obvious advantage of the method.

The Marconi Company has arranged a series of historical exhibits illustrating the development of wireless apparatus. Another exhibit of this firm shows how one type of echometer can indicate to a trawler the depth of the sea-bed and also that at which a shoal of fish may be passing. The Accurate Recording Instrument Co. has working models of a liquidmeter which will very soon be manufactured. This, although very sensitive and carefully compensated, is of a robust construction and is not likely to get out of order. It operates by means of two pairs of opposed hydraulic bellows so that the displacements made in the tank are exactly reproduced at the dial. Among other recording instruments, Messrs. Radiovisor show the counting unit such as is used in the Mersey Tunnel to give a record of vehicles entering and also in factories for counting sacks, tins, etc., by the interception of a beam of light.

Of the many Diesel engines on view, that of the Brush Electrical Engineering Co. Ltd. will be of considerable interest to engineers. It is a horizontal type and has four cylinders arranged in pairs on opposite sides of the crankshaft. An independent test by Mr. W. A. Tookey showed the fuel consumption to be $0 \cdot 357 \mathrm{lb}$. per B.H.P. hour when developing 250 B.H.P. at a speed of 250 r.p.m.

The exhibit, however, which takes the highest place in scientific importance and which at the same time appeals to all who are mechanically minded is that of the Department of Scientific and Industrial Research and associated bodies. It illustrates researches carried out in engineering and metallurgy, showing how the tests are made on models of ships' hulls and propellers, on coal, on the transport and storage of food and on fire resistance of structures. By the use of short films the visitor sees more than the mere instruments and materials of the test; he is enabled to follow the course and operations of the investigation. 